\title{
Effects of ghrelin in energy balance and body weight homeostasis
}

\author{
Laura Mihalache, ${ }^{1}$ Andreea Gherasim, ${ }^{1}$ Otilia Niță, ${ }^{1}$ Maria Christina Ungureanu, ${ }^{1}$ \\ Sergiu Serghei Pădureanu, ${ }^{2}$ Radu Sebastian Gavril, ${ }^{1}$ Lidia Iuliana Arhire ${ }^{1}$
}

${ }^{1}$ Department of Internal Medicine, ${ }^{2}$ Department of Surgery, "Grigore T. Popa" University of Medicine and Pharmacy, lassy, Romania

\begin{abstract}
Ghrelin is a gut peptide composed of 28 amino acids mostly secreted in the gastric fundus mucosa. It was isolated and described in 1999 by Kojima et al. and only three years later its specific receptor, GHSR1a, was also identified. Ghrelin, the endogenous ligand for the GH secretagogue receptor, is the only peripheral orexigenic hormone that activates the receptors to be found especially in the appetite center (hypothalamus and pituitary gland). Ghrelin is present in human plasma in two forms: an inactive form known as deacylated ghrelin, and an active form called acylated ghrelin synthesized under the action of ghrelin $\mathrm{O}$-acyltransferase enzyme (GOAT). The literature even mentions an extremely complex ghrelin/GOAT/GHSR system involved in the regulation of human energy, metabolism and adaptation of energy homeostasis to environmental changes. In humans, there is a preprandial rise and a postprandial fall in plasma ghrelin levels, which strongly suggest that the peptide plays a physiological role in meal initiation and may be employed in determining the amount and quality of ingested food. Besides the stimulation of food intake, ghrelin determines a decrease in energy expenditure and promotes the storage of fatty acids in adipocytes. Thus, in the human body ghrelin induces a positive energy balance, an increased adiposity gain, as well as an increase in caloric storage, seen as an adaptive mechanism to caloric restriction conditions. In the current world context, when we are witnessing an increasing availability of food and a reduction of energy expenditure to a minimum level, these mechanisms have become pathogenic. As a consequence, the hypothesis that ghrelin is involved in the current obesity epidemic has been embraced by many scholars and researchers
\end{abstract}

Key words: Appetite, Energy balance, Ghrelin

Address for correspondence:

Andreea Gherasim, Department of Internal Medicine, "Grigore

T. Popa" University of Medicine and Pharmacy, Iassy, Romania;

E-mail: anny_gh2005@yahoo.com

Received: 27-03-2016, Accepted: 16-05-2016

\section{INTRODUCTION}

Ghrelin is a gut peptide composed of 28 amino acids mostly secreted by the gastric fundus mucosa. It was isolated and described in 1999 by Kojima et al and 
three years later its specific receptor, GH secretagogue receptor 1a (GHSR1a), was identified. Ghrelin, the endogenous ligand for GHSR1a, is the only peripheral orexigenic hormone that activates receptors localized in the appetite centers in hypothalamus. Ghrelin is present in human plasma in two forms: an inactive form known as deacylated ghrelin, and an active form, the acylated ghrelin synthesized under the action of ghrelin O-acyltransferase enzyme (GOAT). The literature additionally mentions an extremely complex ghrelin/GOAT/GHSR system involved in the regulation of human energy and metabolism and the adaptation of energy homeostasis to environmental changes. In humans, there is a preprandial rise and a postprandial fall in plasma ghrelin levels, which strongly suggest that the peptide plays a physiological role in meal initiation, while it is also employed in determining the amount and quality of ingested food. Besides the stimulation of food intake, ghrelin brings about a decrease in energy expenditure and promotes the storage of fatty acids in adipocytes. Thus, in the human body ghrelin induces a positive energy balance, an increased adiposity gain, as well as an increase in caloric storage, seen as an adaptive mechanism to caloric restriction conditions. In the current global context when we are witnessing an increasing availability of food and a reduction of energy expenditure to a minimum level, these mechanisms have become pathogenic. As a consequence, the hypothesis that ghrelin is involved in the current obesity epidemic has been embraced by many scholars and researchers. This review aims to analyze currently existing data on ghrelin involvement in regulating the human body energy balance.

\section{GHRELIN - A PERIPHERAL OREXIGENIC PEPTIDE WITH CENTRAL ACTION}

It is known and has been abundantly demonstrated that in both animals and human subjects, ghrelin increases appetite and stimulates food intake in a GH-independent manner ${ }^{1}$ through its specific receptor GHSR1a. ${ }^{2}$ Numerous data in the literature have supported findings providing evidence that, besides exerting an orexigenic effect, this ghrelin/GOAT/GHSR system is involved in regulating energy metabolism and its adjustment to energy balance changes. ${ }^{3}$ The circulating levels of ghrelin are elevated during fasting and before meals ${ }^{4-6}$ and decline postprandially, ${ }^{5-7}$ which implies that ghrelin plays a significant role in initiating food intake. ${ }^{8}$ The increased level of ghrelin during fasting ${ }^{9}$ is a unique phenomenon in human physiology, which contrasts with the secretion levels of most gut hormones that increase during nutrient intake and decrease during fasting. ${ }^{8}$ Another peculiarity of ghrelin is that although it is a peripherally-secreted peptide in the gastrointestinal tract, it has major effects upon the central nervous system (CNS). ${ }^{1}$ Ghrelin is synthesized and secreted primarily in the stomach ${ }^{10}$ (oxintic mucosa X/A-like cells are immunoreactive cells for ghrelin, being more numerous in the gastric fundus and progressively decreasing towards the pylorus ${ }^{11}$ ), but low levels of ghrelin expression can also be found in other tissues such as the bowel, pancreas, kidney, ovary or brain. ${ }^{12}$ Accordingly, positive immunoreactivity for ghrelin was described in the hypothalamic arcuate nucleus, ${ }^{1}$ an extremely important region for appetite control, and in the internuclear space of the lateral hypothalamus, hypothalamic arcuate, ventromedial, dorsomedial and paraventricular nuclei and ependymal layer of the third ventricle. ${ }^{13}$ To exert its orexigenic action, ghrelin reaches the hypothalamus in three different ways: systemically by crossing the blood-brain barrier, via the vagal afferents and via local hypothalamic synthesis and secretion, thereby exerting paracrine actions. ${ }^{14}$

In humans initiating meals voluntarily without time- and food-related cues, plasma ghrelin levels increase before meals and display a temporal profile similar to hunger scores, ${ }^{15}$ once again confirming the hypothesis that ghrelin is a physiological meal initiator. Food intake or gastric/enteral feeding causes the suppression of circulating ghrelin levels. ${ }^{16}$ Moreover, the composition of ingested foods appears to influence ghrelin secretion, albeit the published studies report conflicting results in this regard. In fact, two different situations have been observed: more significantly decreased levels of ghrelin after the ingestion of proteins and carbohydrates than those observed after the ingestion of lipids; $;^{17,18}$ lower ghrelin levels after lipids that after carbohydrate or protein intake. ${ }^{19}$

However, most research teams have concluded that the circulating levels of ghrelin decrease after meals regardless of the type of nutrients consumed (carbohydrates and proteins still remaining the most 
potent inhibitors), ${ }^{20}$ these interprandial changes in circulating ghrelin levels being found only in normal weight individuals. ${ }^{21}$ Ghrelin is the only currently known orexigenic gastrointestinal peptide which, in addition to appetite stimulation, increases the number of meals and also shortens latency to eat. ${ }^{20}$ Ghrelininduced hyperphagia was hence considered as one of the mechanisms involved in the development of overweight.

Recent studies have demonstrated that ghrelin also acts on the dopaminergic regions of the limbic system. ${ }^{22}$ Moreover, ghrelin stimulates brain activity in certain regions involved in controlling eating behaviour, such as the amygdale and the orbitofrontal cortex. ${ }^{23-25}$ Thus, besides the demonstrated classic effect of appetite stimulation through hypothalamic circuits, ghrelin may be involved in regulating eating behaviour. $^{16}$

Ghrelin stimulates food intake in an acute manner, inducing meal initiation. ${ }^{26}$ Initially, many experimental studies on laboratory animals showed that the administration of ghrelin increased the urge to eat and look for food, ${ }^{27}$ without influencing the hedonic aspects of eating. But at the central level there are nuclei expressing ghrelin receptors that are associated with the intake of high-palatability foods. This may explain why in a food preference test the central administration of ghrelin shifts food choice towards a hyperlipid diet. ${ }^{28}$ Therefore, ghrelin stimulates the intake of high energy density, high-fat, high-palatability foods, regardless of the type of nutrient normally preferred. ${ }^{20}$ Ghrelin administration in laboratory mice caused increasing intake of palatable saccharin solutions and preference for food with saccharin..$^{29}$ In normal human subjects, ghrelin administration, besides increasing appetite and caloric intake, also stimulates imagination of favourite meals ${ }^{30}$ and external visual stimuli represented by hedonic foods increases ghrelin levels. ${ }^{31}$ In addition to meal initiation, ghrelin increases meal duration and size in the context of regularly scheduled meals. ${ }^{32}$ The distribution of specific receptors for ghrelin as well as the study of MRI images confirm the hypothesis that ghrelin not only stimulates appetite but is also involved in regulating the hedonic aspects of eating: the preference for palatable foods, the motivation to obtain one's preferred foods, the reward value/effect of one's preferred foods and the actual purchase of foods. ${ }^{33,34}$ Recent data indicate that ghrelin also influences behaviours related to motivational aspects of eating. Thus, currently existing evidence suggests that the ghrelin/GOAT/GHSR1a system is closely linked to pathways involved in reward aspects of food intake, additionally and partially separated from those determining food intake initiation. ${ }^{35}$ Mediation of this eating behaviour response by ghrelin is accomplished through the dopaminergic neural network extending from the ventral tegmental area and other brain nuclei and finally resulting in food intake depending on its reward aspects. ${ }^{36}$

Hence, at the mesolimbic level, ghrelin would produce increased hedonic aspects of eating and increase motivation to seek and procure food, initiating anticipatory activity and foraging behaviours. ${ }^{35}$ Based on these aspects, some researchers have proposed the clinical use of ghrelin in cases in which increased levels of food intake may be beneficial, such as elderly patients with nutritional deficiencies ${ }^{37}$ or with anorexia associated with different consumption diseases. ${ }^{38}$

Ghrelin is considered an orexigenic signal (gutbrain) for the control of appetite and energy balance in healthy individuals. GHSR 1a, the ghrelin-specific receptor, binds acylated ghrelin and mainly induces the release of the growth hormone from the somatotropic cells in the anterior pituitary gland. Via the vagus nerve or directly at the central level, ghrelin activates the neurons in the arcuate nucleus (ARC nucleus) secreting orexigenic peptides - neuropeptide Y (NPY) and agouti-related peptide (AgRP) ${ }^{39}$ - and inhibits the anorexigenic neurons secreting pro-opiomelanocortin and $\alpha$-melanocyte-stimulating hormone. Orexigenic signals act via adenosine monophosphate-activated protein kinase (AMPK) and increase the dopaminergic transmission from the ventral tegmental area to the nucleus accumbens, enhancing the reward signals. ${ }^{40}$ Therefore, the binding of ghrelin to its specific receptor GHSR1a will lead to an increase in intracellular calcium concentration, with consequent activation of CaMKK2 (calmodulin kinase-kinase 2), which will phosphorylate AMPK.$^{41}$ In its turn, AMPK will phosphorylate and inhibit acetyl-coenzyme A carboxylase, resulting in decreased levels of malonyl-CoA and subsequent activation of carnitine-palmitoyltransferase- $1 .{ }^{42}$ The end result of this long series of enzymatic reactions is increased mitochondrial $\beta$-oxidation, with the gen- 
eration of reactive oxygen species and stimulation of uncoupling protein 2 (UCP2), ${ }^{43}$ which will stimulate NPY/AgRP transcription. ${ }^{44}$

In pathologic states, ghrelin may be decreased (in obesity) or increased (in anorexia nervosa, cachexia or Prader-Willi syndrome), which promotes speculation about the therapeutic applications of both ghrelin agonists and antagonists in these states. ${ }^{45}$ It is hence evident that the metabolic status plays a key role in ghrelin function. Ghrelin activates NPY/agoutirelated protein (AgRP) neurons through fatty acid oxidation and maintains NPY/AgRP cell function during extended periods of negative energy balance. Meanwhile, ghrelin is also required to maintain normal blood sugar levels during severe caloric restriction. Ghrelin is a key modulator of energy metabolism during starvation or long periods of negative energy balance. Recent studies have shown that in patients with diet-induced obesity (DIO) there is resistance to ghrelin in the arcuate NPY/AgRP neurons. In this case, the level of circulating ghrelin, the overall level of ghrelin as well as that of the GOAT mRNA in the stomach and that of the GHSR in the hypothalamus are all decreased. ${ }^{46}$

\section{GHRELIN - A REGULATOR OF GASTROINTESTINAL FUNCTIONS}

Acylated ghrelin is a potent stimulator of gastric secretion and motility. ${ }^{47}$ On the one hand, ghrelin stimulates the secretion of gastric acid and digestive enzymes in the digestive organs within the digestive/ gastrointestinal (GI) tract (stomach, intestine, and pancreas). ${ }^{48,49}$ On the other hand, ghrelin reduces the gastrointestinal transit time of ingested nutrients, accelerating gastric emptying and stimulating the motility in the small intestine and colon. ${ }^{50}$ These prokinetic and prosecretory effects, coupled with the modulation of eating behaviour actually facilitate digestion and absorption processes. ${ }^{8}$ However, by decreasing the intestinal transit time, ghrelin limits the feedback from digestive tract/GI satiety signals, which should determine termination of food intake. ${ }^{20}$

\section{GHRELIN AND WEIGHT STATUS}

The energy homeostasis/balance of the human body and therefore its weight stability is reached when there is a balance between energy intake and expenditure, the two arms of the energy balance. As a result, weight loss will occur when the caloric intake is decreased and/or the energy expenditure is increased, while weight gain will occur when the caloric intake is increased and/or the energy expenditure is reduced. Due to its appetite stimulating effect, ghrelin is an enteroendocrine peptide that induces weight gain and adiposity. ${ }^{51,52}$ Interestingly enough, there is also a preferential effect on fat intake that has recently been demonstrated. ${ }^{28}$ Additionally, ghrelin would seem to promote adipose tissue deposition, ${ }^{39}$ reduced energy expenditure and more efficient storage of lipids. ${ }^{39,53}$ It can be said that ghrelin acts to protect the energy resources of the body when these are available (defensive role, protecting against hypoglycaemia that may occur in conditions of prolonged caloric restriction) ${ }^{54}$ to redirect the metabolism to storing excess calories for later use in case of food insufficiency. Some authors have suggested that ghrelin is the factor that modulates feeding behaviour towards energy accumulation, ${ }^{50,55}$ which is not beneficial to the human body in the current circumstances, as we often witness at the individual level a positive energy balance oriented to excessive caloric intake associated with reduced energy expenditure mainly because of our present-day sedentary lifestyle. Thus, what should be a protective mechanism against starvation is currently a pathological mechanism geared towards obesity and its complications.

Ghrelin acting through GHS-R theoretically causes weight gain based on the increase in height of individuals and/or lean tissue, similar to GH administration. Basically, the available data clearly demonstrate that central or peripheral administration of ghrelin increases the body fat mass, ${ }^{26}$ adipogenesis and lipogenesis (by increasing PPAR $\gamma$ level), with concomitant reduction of lipolysis and use of lipids as energy substrates. ${ }^{56}$ It is worth mentioning that these adipogenic effects appear to be independent from the orexigenic effect of ghrelin, ${ }^{8,57}$ this being all the more interesting because of its influence on energy metabolism. Data derived from studies on laboratory animals show, in fact, an effect of stimulating differentiation and proliferation of preadipocytes. ${ }^{58}$

Plasma ghrelin levels are negatively correlated with body mass index and body fat percentage, being 
considered a "reverse adiposity signal". ${ }^{20}$ Accordingly, recent studies have demonstrated that obese people have low ghrelin levels ${ }^{59}$ while patients with anorexia have high plasma ghrelin levels ${ }^{60}$ compared with healthy normal weight subjects. Moreover, variations in body weight (weight gain or loss) were observed to lead to compensatory responses of ghrelin levels. ${ }^{56}$ For example, weight loss (whether resulting from reduced food intake or increased energy expenditure through physical activity) is accompanied by an increase in ghrelin level. ${ }^{61}$ In its turn, weight gain (due to excessive caloric intake, high-fat diets, or else iatrogenic or pregnancy-related ${ }^{56,62}$ is accompanied by a decrease in ghrelin levels. Reduced ghrelin secretion in obese patients was found to be an adaptive mechanism to a long-term positive energy balance. Although circulating plasma ghrelin levels are low in obese people, a lack of postprandial ghrelin suppression was observed, which could contribute to increased food intake in these people. ${ }^{49}$

Obesity, especially diet-induced obesity (DIO), would produce resistance to ghrelin both peripherally and centrally. In the stomach, ghrelin-secreting cells stop responding to such stimuli as norepinephrine and glucose and central appetite can no longer be increased by the alteration of neural circuits regulating homeostatic feeding and reward processing pathways. Diets inducing weight loss reduce this resistance, pointing to possible defence mechanisms of body weight set-point established during times of food availability. ${ }^{63}$ Voluntary weight loss secondary to low-calorie diets is accompanied by an increase in circulating ghrelin levels, leading to increased hunger sensation and therefore food intake. ${ }^{64}$ As a result, attractive hypotheses have been put forward regarding the mechanism of repetitive weight gain in patients on cyclic diets, which can partially explain the present obesity epidemic.

It was noted that in obesity leptin levels are increased, while ghrelin levels are decreased, ${ }^{60}$ which points to the adaptation of these two hormones to the positive energy balance and not necessarily their involvement in the determinism of obesity.

The conflicting results regarding ghrelin levels after metabolic surgery must be mentioned. In this situation, postsurgical weight loss caused different fluctuations in ghrelin levels: either an increase ${ }^{65,66}$ or a decrease in plasma ghrelin ${ }^{67,68}$ or, in some cases, no changes ${ }^{69}$ This variability in circulating ghrelin levels after metabolic surgery attracted the interest of numerous research teams in attempting to elucidate the mechanisms of postoperative weight loss. Several mechanisms have been proposed to explain these conflicting results: ${ }^{70}$ either the differences in the surgical techniques employed that are related to the manipulation of the digestive tract and removal of certain portions involved or not in ghrelin secretion; or individual differences in the speed of postsurgical weight loss and in reaching a relatively stable body mass index. Recent data even demonstrate that high preoperative circulating ghrelin levels could identify patients with a susceptibility to weight regain 1-2 years after metabolic surgery. ${ }^{71}$ Further studies are needed to confirm/refute these hypotheses and to clarify the mechanisms of weight loss following metabolic surgery and, more crucially, the mechanisms for maintaining the new weight in the long term.

One exception that is frequently mentioned in the literature is that of patients with Prader-Willi syndrome who, although obese, have circulating ghrelin levels much higher compared to normal weight individuals (a condition termed by some authors "hereditary hyperghrelinemia"). ${ }^{8}$ Moreover, these patients do not present the postprandial ghrelin kinetics: the circulating level is not reduced after food intake or the decline is much less compared to obese or normal weight individuals..$^{60}$ The above initial data produced enthusiasm among some authors who have suggested that these may explain, at least partially, the increased appetite (almost uncontrollable) of these patients and the high incidence of obesity. However, although research has continued, the consequences of high levels of ghrelin in these patients are still unclear and controversial. Nevertheless, recent studies confirm that total levels of plasma ghrelin are highest in children with Prader-Willi syndrome early in life when they are characterized, during the nutritional phases, by reduced appetite and reduced food intake, i.e. long before the onset of hyperphagia, ${ }^{72}$ while changing plasma ghrelin levels were not associated with a transition to the hyperphagic phase. ${ }^{73}$ It is noteworthy that both studies mentioned analyzed total plasma and not acylated ghrelin. However, other hypotheses 
have arisen to explain the increased appetite of these patients and excessive weight gain which propose that it concerns alterations of cortical and subcortical regions involved in reward aspects of eating along with other neural circuits (abnormal or delayed development of effective pathways of this hormone, altered sensitivity of the neural transmission). ${ }^{73,74}$

\section{GHRELIN AND INTERMEDIARY METABOLISMS}

Ghrelin is a gastrointestinal peptide with a major role in the regulation of glucose homeostasis as an integral part of body energy metabolism. Both ghrelin and its receptors are also present in pancreatic islet cells, ${ }^{75}$ implying that ghrelin exerts paracrine and autocrine actions in the pancreas. ${ }^{76}$ Consequently, the interest of many research teams has been directed towards investigating the role of ghrelin in the regulation of glucose homeostasis. In this regard, in vitro and in vivo studies involving both animals and humans were conducted to elucidate the ghrelin-insulin-glucagon interactions. As to the action of ghrelin on plasma insulin levels, the results are also contradictory, with some studies showing that ghrelin stimulates insulin secretion in the presence of hyperglycemia ${ }^{9,77,78}$ and others finding no change in insulinemia under normoglycemic conditions. ${ }^{79-81}$ There are also studies that demonstrate the hyperglycemic effect of ghrelin secondary to decreased insulin secretion, ${ }^{79,82}$ thus indicating that ghrelin may be a diabetogenic factor. ${ }^{83}$ However, the various effects of ghrelin on insulin secretion reported in the literature seem to correlate with the individual level of glycemic control. ${ }^{84,85}$ If we look at the studies in their entirety, the published results demonstrate that acute administration of physiological and pharmacological doses of ghrelin inhibits glucose-dependent insulin secretion, ${ }^{80,86}$ while supraphysiological doses of ghrelin may even decrease peripheral insulin sensitivity. ${ }^{87}$ The longterm effects of ghrelin on carbohydrate metabolism have undergone fewer studies in humans. The use of a ghrelin mimetic for 1 year resulted in increased basal glucose level and decreased insulin sensitivity estimated by the Quicki index. ${ }^{88}$ In its turn, circulating ghrelin levels are influenced by insulinemia levels. A recent study in healthy volunteers demonstrated that acylated ghrelin levels are low under hyperinsulinemia conditions, followed by a subsequent increase in plasma ghrelin levels. ${ }^{89}$ The authors even suggested that this fluctuation in ghrelin levels in response to acute hyperinsulemia would contribute to a rise of hunger sensation and therefore of food intake which are indeed observed after episodes of hypoglycemia. ${ }^{89}$

Studies in animal models have demonstrated that ghrelin increases hepatic glucose production ${ }^{62}$ by activating the gluconeogenic processes and/or via GH (which in its turn causes an increased hepatic glucose production).$^{57}$ Concomitantly, ghrelin blocks the ability of insulin to suppress endogenous glucose production. ${ }^{62}$ Additionally, ghrelin inhibits the secretion of adiponectin (acting as an insulin sensitizer) and stimulates the secretion of counterregulatory hormones (glucagon, cortisol, GH, adrenaline). Data in the literature have also indicated the existence of a feedback loop between ghrelin and glucagon. ${ }^{57}$ Thus, ghrelin directly stimulates glucagon secretion from pancreatic $\alpha$ cells (via GHS-R), ${ }^{90}$ while glucagon stimulates ghrelin secretion under nutrient-deficient conditions. ${ }^{91}$ Studies on laboratory animals have revealed that under the action of acyl-ghrelin, fat is stored not only in adipose tissue but also the liver, ${ }^{39}$ where an increase in triacylglycerol content and genes involved in hepatic lipogenesis was found..$^{92}$

A recent study published by Gagnon et al. brought up for discussion a new aspect of ghrelin involvement in glucose regulation, the authors demonstrating that ghrelin increases the secretion of GLP-1 (glucagon like peptide 1), thereby improving glucose tolerance. ${ }^{93}$ They concluded that ghrelin is a "GLP-1 secretagogue". ${ }^{93}$

All these results emphasize the complexity of the relationship between ghrelin and pancreatic $\beta$-cell; however, this is a topic that is still open for research. For this reason, although initial data related to ghrelin involvement in appetite control have attracted a great amount of interest as a potential therapeutic option in weight control, most researchers are cautious about its actual use until the involvement of ghrelin in carbohydrate metabolism has been elucidated.

\section{GHRELIN AND ENERGY EXPENDITURE}

Besides its major influence on energy intake, ghrelin exerts important effects on energy expenditure. Studies on laboratory mice have shown that administration of 
anti-ghrelin antibodies increases energy expenditure, ${ }^{57}$ this demonstrating the complex role they play in the adjustment of body energy balance by acting on both components (both caloric intake and reduced energy consumption). Ghrelin receptor GHS-R is an important regulator of thermogenesis. ${ }^{57}$ The ablation of this receptor increases energy expenditure by increasing thermogenesis in brown adipose tissue (by uncoupling oxidative phosphorylation from electron transport chain due to increased UCP1 expression), ${ }^{52,94}$ which is independent of food intake or physical activity. ${ }^{57}$ This finding has significant practical implications since it has been proposed that GHS-R antagonists may represent a new therapeutic class effective in obesity ${ }^{94}$ and not requiring restrictive diets or physical activity.

In addition to decreased thermogenesis, ghrelin also decreases energy expenditure by reducing the activity of the sympathetic nervous system (SNS), especially in brown adipose tissue. ${ }^{95}$

Another aspect, possibly less studied, is that of ghrelin as a potential clinical marker of catabolism. ${ }^{60}$ This hypothesis was based on the findings that increased circulating ghrelin levels are found in patients with cachexia associated with chronic heart failure, liver cirrhosis or neoplastic disease, and in patients with chemotherapy-induced anorexia (all these conditions being characterized by hypercatabolism) ${ }^{62}$ It had been experimentally demonstrated that $\mathrm{GH}$ secretagogues have the ability to reverse the catabolic effects and to improve the somatotroph axis alterations and protein catabolism in patients with severe, prolonged diseases characterized by hypercatabolism. ${ }^{96}$ Due to its anabolic effects, GH has already been used to prevent muscle loss associated with surgical stress, sepsis, HIV/ AIDS and malignancies. ${ }^{97}$ In this respect, ghrelin, or any other compound stimulating GH secretion, would improve the therapeutic outcomes in these patients, particularly in elderly patients in whom the association of reduced GH secretion, reduced muscle mass and anorexia is often present. Studies aimed at evaluating the efficacy of ghrelin treatment in patients with anorexia-cachexia syndrome associated with neoplastic disease are needed, as a so-called resistance to ghrelin has been suggested.

In conclusion, circulating ghrelin level in humans are low under conditions of positive energy balance,

Table 1. The main effects of ghrelin that can influence energy metabolism

\begin{tabular}{ll}
\hline Food intake ${ }^{1,35}$ & $\uparrow$ appetite $\uparrow$ food intake \\
& $\uparrow$ hedonic aspect of eating \\
& $\uparrow$ motivation to obtain food \\
& $\uparrow$ food seeking behaviours \\
& $\uparrow$ gastric motility \\
& $\uparrow$ gastric acid secretion and digestive enzymes \\
Gastrointestinal function ${ }^{47-50}$ & $\uparrow$ lipogenesis \\
& $\uparrow$ adipogenesis $(\uparrow$ differentiation and proliferation of preadipocytes) \\
Adipose tissue ${ }^{26,39,53,58}$ & $\downarrow$ lipid oxidation \\
& $\downarrow$ insulin secretion \\
& $\uparrow$ hepatic gluconeogenesis \\
Intermediary metabolisms & $\downarrow$ insulin sensitivity \\
& $\uparrow$ glucagon secretion \\
& $\uparrow$ hepatic lipogenesis \\
& GLP-1 secretagogue \\
& $\downarrow$ energy expenditure \\
Energy expenditure & $\downarrow$ thermogenesis in BAT \\
$\downarrow$ sympathetic nervous system in BAT &
\end{tabular}


either in acute conditions (food intake) or chronic conditions (obesity). Elevated circulating ghrelin levels are found in fasting conditions and in patients with anorexia of various causes. One can therefore conclude that ghrelin levels correlate inversely with body energy stores. The increased levels of ghrelin right before meals suggests that it is a meal initiator or hunger signal, being involved in meal duration and size and in the hedonic aspects of nutrition. The administration of ghrelin generates a positive energy balance and increases adiposity while reducing energy expenditure. However, ghrelin seems to exert more complex effects (summarized in Table 1), playing a major role in the modulation of intermediary metabolisms and their integration into the metabolic economy of our body. Simultaneously, ghrelin has a central role in controlling the energy balance, integrating the peripheral signals and central effectors that determine our eating behaviour.

\section{FUNDING}

This research was financed by the "Grigore T. Popa" University of Medicine and Pharmacy by contract no. 30887/30.12.2014.

\section{REFERENCES}

1. Kojima M, Hosoda H, Date M, Nakazato M, Matsuo H, Kangawa K, 1999 Ghrelin is a growth-hormone-releasing acylated peptide from stomach. Nature 402: 656-660.

2. Howard AD, Feighner SD, Cully DF, et al, 1996 A receptor in pituitary and hypothalamus that functions in growth hormone release. Science 273: 974-977.

3. Laviano A, Mari A 2014 Homodimerization and heterodimerization of the ghrelin receptor. In: Portelli J, Smolders I (eds), Central functions of the ghrelin receptor. Humana Press, Springer Science New York; pp, 21-34.

4. Cummings DE, Purnell JQ, Frayo RS, Schmidova K, Wisse BE, Weigle DS, 2011 A preprandial rise in plasma ghrelin levels suggests a role in meal initiation in humans. Diabetes 50: 1714-1719.

5. Natalucci G, Riedl S, Gleiss A, Zidek T, Frisch H, 2005 Spontaneous 24-h ghrelin secretion pattern in fasting subjects: maintenance of a meal-related pattern. Eur J Endocrinol 152: 845-850.

6. Liu J, Prudom CE, Nass R, et al, 2008 Novel ghrelin assays provide evidence for independent regulation of ghrelin acylation and secretion in healthy young men. J Clin Endocrinol Metab 93: 1980-1987.

7. Tschöp M, Wawarta R, Riepl RL, et al, 2001 Post- prandial decrease of circulating human ghrelin levels. J Endocrinol Invest 24: RC19-21.

8. Chen CY, Asakawa A, Fujimiya M, Lee SD, Inui A, 2009 Ghrelin gene products and the regulation of food intake and gut motility. Pharmacol Rev 61: 430-481.

9. Lee HM, Wang G, Englander EW, Kojima M, Greeley GH Jr, 2002 Ghrelin, a new gastrointestinal endocrine peptide that stimulates insulin secretion: enteric distribution, ontogeny, influence of endocrine, and dietary manipulations. Endocrinology 143: 185-190.

10. Sakata I, Nakamura K, Yamazaki M, et al, 2002 Ghrelinproducing cells exist as two types of cells, closed- and opened-type cells, in the rat gastrointestinal tract. Peptides 23: 531-536.

11. Date Y, Kojima M, Hosoda H, et al, 2000 Ghrelin, a novel growth hormone-releasing acylated peptide, is synthesized in a distinct endocrine cell type in the gastrointestinal tracts of rats and humans. Endocrinology 141: 4255-4261.

12. Castañeda TR, Tong J, Datta R, Culler M, Tschöp MH, 2010 Ghrelin in the regulation of body weight and metabolism. Front Neuroendocrinol 31: 44-60.

13. Cowley MA, Smith RG, Diano S, et al, 2003 The distribution and mechanism of action of ghrelin in the CNS demonstrates a novel hypothalamic circuit regulating energy homeostasis. Neuron 37: 649-661.

14. Lim CT, Kola B, Korbonits M, 2011 The ghrelin/GOAT/ GHS-R system and energy metabolism. Rev Endocr Metab Disord 12: 173-186.

15. Cummings DE, Frayo RS, Marmonier C, Aubert R, Chapelot D, 2004 Plasma ghrelin levels and hunger scores in humans initiating meals voluntary without time- and food-related cues. Am J Physiol Endocrinol Metab 287: E297-304.

16. De Vriese C, Perret J, Delporte C, 2010 Focus on the short- and long-term effects of ghrelin on energy homeostasis. Nutrition 26: 579-584.

17. Overduin J, Frayo RS, Grill HJ, Kaplan JM, Cummings DE, 2005 Role of the duodenum and macronutrient type in ghrelin regulation. Endocrinology 146: 845-850.

18. Foster-Schubert KE, Overduin J, Prudom CE, et al, 2008 Acyl and total ghrelin are suppressed strongly by ingested proteins, weakly by lipids, and biphasically by carbohidrates. J Clin Endocrinol Metab 93: 1971-1979.

19. Beck B, Richy S, 2008 Differential long-term dietary regulation of adipokines, ghrelin, or corticosterone: impact on adiposity. J Endocrinol 196: 171-179.

20. Covasa M, Swartz T 2011 The role of ghrelin in eating behaviour. In: Preedy VR, Watson RR, Martin CR (eds), Handbook of behavior, food and nutrition. Springer Science, New York; pp, 175-188.

21. Blom WA, de Graaf C, Lluch A, Stafleu A, Schaafsma G, Hendriks HF, 2009 Postprandial ghrelin responses are associated with the intermeal interval in time-blinded normal weight men, but not in obese men. Physiol Behav 96: 742-748. 
22. Cone JJ, Roitman JD, Roitman MF, 2015 Ghrelin regulates phasic dopamine and nucleus accumbens signaling evoked by food-predictive stimuli. J Neurochem 133: 844-856.

23. Malik S, McGlone F, Bedrossian D, Dagher A, 2008 Ghrelin modulates brain activity in areas that control appetite behaviour. Cell Metab 7: 400-409.

24. Sun X, Veldhuizen MG, Wray AE, et al, 2014 The neural signature of satiation is associated with ghrelin response and triglyceride metabolism. Physiol Behav 136: 63-73.

25. Stoyanova II, 2014 Ghrelin: a link between ageing, metabolism and neurodegenerative disorders. Neurobiol Dis 72: 72-83.

26. Van der Lely AJ, Tschöp M, Heiman ML, Ghigo E, 2004 Biological, physiological, pathophysiological, and pharmacological aspects of ghrelin. Endocr Rev 25: 426-457.

27. Skibicka KP, Dickson SL, 2013 Enteroendocrine hormones - central effects on behaviour. Curr Opin Pharmacol 13: 977-982.

28. Shimbara T, Mondal MS, Kawagoe T, et al, 2004 Central administration of ghrelin preferentially enhances fat ingestion. Neurosci Lett 369: 75-79.

29. Disse E, Bussier AL, Veyrat-Durebex C, et al, 2010 Peripheral ghrelin enhances sweet taste food consumption and preference, regardless of its caloric content. Physiol Beh 101: 277-281.

30. Schmid DA, Held K, Ising M, et al, 2005 Ghrelin stimulates appetite, imagination of food, GH, ACTH, and cortisol, but does not affect leptin in normal controls. Neuropsychopharmacology 30: 1187-1192.

31. Schüssler P, Kluge M, Yassouridis A, Dresler M, Uhr M, Steiger A, 2012 Ghrelin levels increase after pictures showing food. Obesity 20: 1212-1217.

32. Overduin J, Figlewicz DP, Bennett-Jay J, Kittleson S, Cummings DE, 2012 Ghrelin increases the motivation to eat, but does not alter food palatability. Am J Physiol Regul Integr Comp Physiol 303: R259-269.

33. Egecioglu E, Skibicka KP, Hansson C, et al, $2011 \mathrm{He}-$ donic and incentive signals for body weight control. Rev Endocr Metab Disord 12: 141-151.

34. Perello M, Raingo J 2014 Central ghrelin receptors and food intake. In: Portelli J, Smolders I (eds), Central functions of the ghrelin receptor. Humana Press, Springer Science, New York; pp, 65-88.

35. Perello M, Dickson SL 2015 Ghrelin signalling on food reward: a salient link between the gut and the mesolimbic system. J Neuroendocrinol 27: 424-434.

36. Müller TD, Nogueiras R, Andermann ML, et al, 2015 Ghrelin. Mol Metab 4: 437-460.

37. Sera-Prat M, Palomera E, Roca M, Puig-Domingo M, Mataro Ageing Study Group, 2010 Long-term effect of ghrelin on nutritional status and functional capacity in the elderly: a population-based cohort study. Clin Endocrinol (Oxf) 73: 41-47.

38. Ali S, Chen JA, Garcia JM, 2013 Clinical development of ghrelin axis-derived molecules for cancer cachexia treatment. Curr Opin Support Palliat Care 7: 368-375.

39. Li Z, Mulholland M, Zhang W, 2016 Ghrelin O-acyltransferase (GOAT) and energy metabolism. Sci China Life Sci 59: 281-291.

40. Kola B, Korbonits M, 2009 Shedding light on the intricate puzzle of ghrelin's effects on appetite regulation. J Endocrinol 202: 191-198.

41. Anderson KA, Ribar TJ, Lin F, et al, 2008 Hypothalamic CaMKK2 contributes to the regulation of energy balance. Cell Metab 7: 377-388.

42. Lopez M, Lage R, Saha AK, et al, 2008 Hypothalamic fatty acid metabolism mediates the orexigenic action of ghrelin. Cell Metab 7: 389-399.

43. Stark R, Andrews ZB, 2014 The role of the ghrelin receptor in appetite and energy metabolism. In: Portelli J, Smolders I (eds), Central functions of the ghrelin receptor. Humana Press, Springer Science New York; pp, 35-52.

44. Andrews ZB, Liu ZW, Wallingford N, et al, 2008 UCP2 mediates ghrelin's action on NPY/AgRP neurons by lowering free radicals. Nature 454: 846-851.

45. Solomou S, Korbonits M, 2014 The role of ghrelin in weight-regulation disorders: Implications in clinical practice. Hormones (Athens) 13: 458-475.

46. Briggs DI, Andrews ZB, 2011 Metabolic status regulates ghrelin function on energy homeostasis. Neuroendocrinology 93: 48-57.

47. Kojima M, Kangawa K, 2005 Ghrelin: structure and function. Physiol Rev 85: 495-522.

48. Masuda Y, Tanaka T, Inomata N, et al, 2000 Ghrelin stimulates gastric acid secretion and motility in rats. Biochem Biophys Res Commun 276: 905-908.

49. Sato T, Ida T, Nakamura Y, Shiimura Y, Kangawa K, Kojima M, 2014 Physiological roles of ghrelin on obesity. Obes Res Clin Pract 8: e405-413.

50. Asakawa A, Inui A, Fujimiya M, et al, 2005 Stomach regulates energy balance via acylated ghrelin and desacyl ghrelin. Gut 54: 18-24.

51. Tschop M, Smiley DL, Heiman ML, 2000 Ghrelin induces adiposity in rodents. Nature 407: 908-913.

52. Tsubone T, Masaki T, Katsuragi I, Tanaka K, Kakuma T, Yoshimatsu H, 2005 Ghrelin regulates adiposity in white adipose tissue and UCP1 mRNA espression in brown adipose tissue in mice. Regul Pept 130: 97-103.

53. Wortley KE, Anderson KD, Garcia K, et al, 2004 Genetic deletion of ghrelin does not decrease food intake but influences metabolic fuel preference. Proc Natl Acad Sci USA 101: 8227-8232.

54. McFarlane MR, Brown MS, Goldstein JL, Zhao TJ, 2014 Induced ablation of ghrelin cells in adult mice does not decrease food intake, body weight, or response to high-fat diet. Cell Metab 20: 54-60.

55. Sleeman MW, Spanswick DC, 2014 Starving for ghrelin. Cell Metab 20: 1-2.

56. Delporte C, 2013 Structure and physiological actions 
of ghrelin. Scientifica (Cairo) 2013: 518909.

57. Pradhan G, Samson SL, Sun Y, 2013 Ghrelin: much more than a hunger hormone. Curr Opin Clin Nutr Metab Care 16: 619-624.

58. Choi K, Roh SG, Hong YH, et al, 2003 The role of ghrelin and growth hormone secretagogues receptor on rat adipogenesis. Endocrinology 144: 754-759.

59. Wang WM, Li SM, Du FM, Zhu ZC, Zhang JC, Li YX, 2014 Ghrelin and obestatin levels in hypertensive obese patients. J Int Med Res 42: 1202-1208.

60. Inui A, Asakawa A, Bowers CY, et al, 2004 Ghrelin, appetite, and gastric motility: the emerging role of the stomach as an endocrine organ. FASEB J 18: 439-456.

61. Hill BR, Rolls BJ, Roe LS, De Souza MJ, Williams NI, 2013 Ghrelin and peptide YY increase with weight loss during a 12-month intervention to reduce dietary energy density in obese women. Peptides 49: 138-144.

62. Leite-Moreira AF, Soares JB, 2007 Physiological, pathological and potential therapeutic roles of ghrelin. Drug Discov Today 12: 276-288

63. Zigman JM, Bouret SG, Andrews ZB, 2016 Obesity Impairs the Action of the Neuroendocrine Ghrelin System. Trends Endocrinol Metab 27: 54-63.

64. Peeters TL, 2005 Ghrelin: a new player in the control of gastrointestinal functions. Gut 54: 1638-1649.

65. Holdstock C, Engstrom BE, Ohrvall M, Lind L, Sundbom M, Karlsson FA, 2003 Ghrelin and adipose tissue regulatory peptides: effect of gastric bypass surgery in obese humans. J Clin Endocrinol Metab 88: 3177-3183.

66. Zhou D, Jiang X, Ding W, et al, 2014 Impact of bariatric surgery on ghrelin and obestatin levels in obesity or type 2 diabetes mellitus rat model. J Diabetes Res 2014: 569435 .

67. Roth CL, Reinehr T, Schernthaner GH, Kopp HP, Kriwanek S, Schernthaner G, 2009 Ghrelin and obestatin levels in severely obese women before and after weight loss after Roux-en-Y gastric bypass surgery. Obes Surg 19: 29-35.

68. Major P, Matlok M, Pedziwiatr M, et al, 2015 Changes in levels of selected incretins and appetite-controlling hormones following surgical treatment for morbid obesity. Wideochir Inne Tech Maloinwazyjne 10: 458-465.

69. Mancini MC, Costa AP, de Melo ME, et al, 2006 Effect of gastric bypass on spontaneous growth hormone and ghrelin release profiles. Obesity (Silver Spring) 14: 383-387.

70. Sweeney TE, Morton JM, 2014 Metabolic surgery: action via hormonal milieu changes, changes in bile acids or gut microbiota? A summary of the literature. Best Pract Res Clin Gastroenterol 28: 727-740.

71. Tamboli RA, Breitman I, Marks-Shulman PA, et al, 2014 Early weight regain after gastric bypass does not affect insulin sensitivity but is associated with higher ghrelin levels. Obesity 22: 1617-1622.

72. Kweh FA, Miller JL, Sulsona CR, et al, 2015 Hyperghrelinemia in Prader-Willi Syndrome begins in early infancy long before the onset of hyperphagia. Am J Med Genet A 167A: 69-79.

73. Goldstone AP, Holland AJ, Butler JV, Whittington JE, 2012 Appetite hormones and the transition to hyperphagia in children with Prader-Willi syndrome. Int J Obes (Lond) 36: 1564-1570.

74. Tzotzas T, Papazisis K, Perros P, Krassas GE, 2008 Use of somatostatin analogues in obesity. Drugs 68: 1963-1973.

75. Wierup N, Sundler F, Heller RS, 2014 The islet ghrelin cell. J Mol Endocrinol 52: R35-49.

76. Kageyama H, Funahashi H, Hirayama M, et al, 2005 Morphological analysis of ghrelin and its receptor distribution in the rat pancreas. Regul Pept 126: 67-71.

77. Date Y, Nakazato M, Hashiguchi S, et al, 2002 Ghrelin is present in pancreatic alpha-cells of humans and rats and stimulates insulin secretion. Diabetes 51: 124-129.

78. Gauna C, Kiewiet RM, Janssen JA, et al, 2007 Unacylated ghrelin acts as a potent insulin secretagogue in glucose-stimulated conditions. Am J Physiol Endocrinol Metab 293: E697-704.

79. Tong J, Prigeon RL, Davis HW, et al, 2010 Ghrelin suppresses glucose-stimulated insulin secretion and deteriorates glucose tolerance in healthy humans. Diabetes 59: 2145-2151.

80. Lucidi P, Murdolo G, Di Loreto C, et al, 2005 Metabolic and endocrine effects of physiological increments in plasma ghrelin concentrations. Nutr Metab Cardiovasc Dis 15: 410-417.

81. Broglio F, Gottero C, Prodam F, et al, 2004 Non-acylated ghrelin counteracts the metabolic but not the neuroendocrine response to acylated ghrelin in humans. J Clin Endocrinol Metab 89: 3062-3065.

82. Broglio F, Arvat E, Benso A, et al, 2001 Ghrelin, a natural GH secretagogue produced by the stomach, induces hyperglycemia and reduces insulin secretion in humans. J Clin Endocrinol Metab 86: 5083-5086.

83. Verhulst PJ, Depoortere I, 2012 Ghrelin's second life: from appetite stimulator to glucose regulator. World $\mathbf{J}$ Gastroenterol 18: 3183-3195.

84. Sato T, Nakamura Y, Shiimura Y, Ohgusu H, Kangawa K, Kojima M, 2012 Structure, regulation and function of ghrelin. J Biochem 151: 119-128.

85. Jain SR, 2014 Ghrelin: a review. J Pharm Sci Res 6: 288-291.

86. Tong J, Prigeon RL, Davis HW, Bidlingmaier M, Tschop MH, D'Alessio D, 2013 Physiologic concentrations of exogenously infused ghrelin reduces insulin secretion without affecting insulin sensitivity in healthy humans. J Clin Endocrinol Metab 98: 2536-2543.

87. Heppner KM, Tong J, 2014 Regulation of glucose metabolism by the ghrelin system: multiple players and multiple actions. Eur J Endocrinol 171: R21-32.

88. Nass R, Pezzoli SS, Oliveri MC, et al, 2008 Effects of an oral ghrelin mimetic on body composition and clinical outcomes in healthy olders adults:a randomized trial. 
Ann Intern Med 149: 601-611.

89. Lauritzen ES, Voss T, Kampmann U, et al, 2015 Circulating acylghrelin levels are suppressed by insulin and increase in response to hypoglycemia in healthy adults volunteers. Eur J Endocrinol 172: 357-362.

90. Chuang JC, Sakata I, Kohno D, et al, 2011 Ghrelin directly stimulates glucagon secretion from pancreatic alpha-cells. Mol Endocrinol 25: 1600-1611.

91. Gagnon J, Anini Y, 2013 Glucagon stimulates ghrelin secretion through the activation of MAPK and EPAC and potentiates the effect of norepinephrine. Endocrinology 154: 666-674.

92. Li Z, Xu G, Qin Y, et al, 2014 Ghrelin promotes hepatic lipogenesis by activation of mTOR-PPARgamma signaling pathway. Proc Natl Acad Sci USA 111: 13163-13168.
93. Gagnon J, Baggio LL, Drucker DJ, Brubaker PL, 2015 Ghrelin is a novel regulator of GLP-1 secretion. Diabetes 64: 1513-1521.

94. Sun Y, 2015 Ghrelin receptor controls obesity by fat burning. Oncotarget 6: 6470-6471.

95. Yasuda T, Masaki T, Kakuma T, Yoshimatsu H, 2003 Centrally administered ghrelin suppresses sympathetic nerve activity in brown adipose tissue of rats. Neurosci Lett 349: 75-78.

96. Broglio F, Arvat E, Benso A, et al, 2002 Ghrelin: much more than a natural growth hormone secretagogue. Isr Med Assoc J 4: 607-613.

97. Akamizu T, Kangawa K, 2010 Ghrelin for cachexia. J Cachexia Sarcopenia Muscle 1: 169-176. 